\title{
INTERNATOS PARA A TERCEIRA IDADE - DADOS INTERNACIONAIS
}

Bastian, E. M. Internatos para a terceira idade - dados internacionais. Rev. Saúde públ., S. Patllo, 13:60-2, 1979.

Resumo: Foram inqueridos iunto a cidades da Europa, Estados Unidos $e$ do Oriente Médio, dados sobre a população de 65 anos $e$ mais, o número de internatos para esta população, e o número de leitos nestes estabelecimentos. Foi calculada a proporção desta população relativa à população total, e o número de pessoas por leito de internato, comparando-se estes dados com os da cidade de São Paulo.

UNITERmos: ldosos. Internatos para idosos. Clinicas de repouso.

Na ocasião de uma pesquisa sobre instituiçōes não-hospitalares para pessoas idosas no Município de São Paulo (Bastian, 1977), foram obtidos dados demográficos de outros paises, ou seja, de municípios de cidades européias, norte-americanas e do oriente médio, com a finalidade de comparação com os dados de São Paulo. Estes dados foram fornecidos por entidades internacionais, oficiais e universitárias.

Foram inqueridas as seguintes informações: população total do município, número de pessoas de 65 anos e mais, número de internatos (não de caráter hospitalar) para estas pessoas, e número de leitos nesses estabelecimentos.

Os resultados do inquérito estão apresentados na Tabela e referem-se à situação do ano de 1975 , no que diz respeito ao número de internatos e leitos. Em relação à população, total e de 65 anos e mais, variaram os anos referência entre $1970 \mathrm{e}$ 1974, de acordo com estimativas e censos intermediários efetuados pelas fontes locais.

Observa-se grande proximidade quanto à proporção da população de 65 anos e mais, entre México, D. C. e São Paulo, ou seja, $3,46 \%$ e $3,49 \%$ respectivamente. Porém, enquanto o México coloca-se no extremo com o número de pessoas (sempre de 65 anos e mais) por leito, isto é, 158,7 pessoas anos e mais) por leito, isto é, 158,7 pessoas, São Paulo está em situação nitidamente superior, com 40,7 pessoas por leito de internato.

Nas cidades dos Estados Unidos a proporção da populaçãa desta faixa etária é menor, variando entre 9,1 e $11,4 \%$, enquanto as cidades européias se colocam entre 10,1 e $20,7 \%$.

A cidade européia com menor proporção, Bucarest com $10,1 \%$, está por sua vez no

* Do Departamento de Prática de Saúde Pública da Faculdade de Saúde Pública da Universidade de São Paulo - Av. Dr. Arnaldo, 715 - 01255 - São Paulo, SP - Brasil. 
BASTIAN, E. M. Internatos para a terceira idade - dados internacionais. Rcv. Saude públ., S. Paulo, 13:60-2, 1979 .

\section{T A B E L A}

População total, número e percentagem da população de 65 anos e mais, número de internatos, de leitos e de leitos por pessoa em cidades de vários países e em São Paulo-Brasil, 1975.

\begin{tabular}{|c|c|c|c|c|c|c|c|}
\hline \multirow{3}{*}{$\begin{array}{l}\text { Cidade } \\
\text { (Municipio) }\end{array}$} & \multirow{3}{*}{ País } & \multicolumn{3}{|c|}{ Populaçăo } & \multirow{3}{*}{$\begin{array}{l}\text { Inter- } \\
\text { natos } \\
\text { No }\end{array}$} & \multirow{3}{*}{$\begin{array}{l}\text { Leitos } \\
\text { No }\end{array}$} & \multirow{3}{*}{$\begin{array}{c}\text { Pessoas } \\
\text { de } 65 \\
\text { anos e } \\
\text { mais, por } \\
\text { leito } \\
\text { Ne }\end{array}$} \\
\hline & & \multirow{2}{*}{$\begin{array}{l}\text { Total } \\
\text { No }\end{array}$} & \multicolumn{2}{|c|}{$\begin{array}{c}\text { De } 65 \text { anos } \\
\text { e mais }\end{array}$} & & & \\
\hline & & & Ne & $\%$ & & & \\
\hline \multicolumn{8}{|l|}{ EUROPA } \\
\hline Bucarest & Romania & $1,642.251$ & 162.317 & 10,1 & 12 & 1.485 & 109,2 \\
\hline Kopenhagen & Dinamarca & 562.403 & 116.550 & 20,7 & 102 & 5.649 & 206 \\
\hline Londres & Inglaterra & 7.167 .600 & 1.007 .100 & 14,1 & 790 & ign. & ign. \\
\hline Munique & Alemanha & 1.293 .590 & 168.209 & 13.0 & $\operatorname{s.ne}$ & 8.461 & 19,6 \\
\hline Viena & Austria & 1.614 .841 & 323.000 & 20,0 & 39 & $10.597^{*}$ & 30,5 \\
\hline Zúrigo & Suíça & 401.577 & 67.899 & 16.9 & 60 & 3.442 & 19.8 \\
\hline \multicolumn{8}{|l|}{$E S T A D O S$} \\
\hline \multicolumn{8}{|l|}{ UNIDOS } \\
\hline Atlanta, & Estados & & & & & & \\
\hline $\mathrm{Ga}$. & Unidos & 496.973 & 45.225 & 9,1 & 21 & 2.034 & 22,2 \\
\hline Chicago & Estados & & & & & & \\
\hline Ill. & Unizos & 3.366 .957 & 356.897 & 10,6 & 145 & 13.313 & 26.7 \\
\hline Detroit, & Estados & & & & & & \\
\hline Mich. & UniJos & 1.511 .482 & 173.148 & 11,4 & 93 & 10.196 & 16,9 \\
\hline $\begin{array}{l}\text { México, } \\
\text { D.C. }\end{array}$ & México & 6.874 .165 & 238.060 & 3,46 & 19 & 1.500 & 158,7 \\
\hline New Orleans, & Estados & & & & & & \\
\hline $\begin{array}{l}\text { La. } \\
\text { Washington, }\end{array}$ & $\begin{array}{l}\text { Unidos } \\
\text { Estados }\end{array}$ & 593.471 & 62.908 & 10,6 & 33 & 2.185 & 28,8 \\
\hline D.C. & Unidos & 756.510 & 71.112 & 9,4 & 73 & 2.774 & 25,6 \\
\hline \multicolumn{8}{|l|}{ ORIENTE } \\
\hline $\begin{array}{l}\text { Tel-Aviv- } \\
\text {-Yafo }\end{array}$ & Israel & 363.750 & 48.742 & 13,4 & 11 & 1.848 & 26,3 \\
\hline \multicolumn{8}{|l|}{$B R A S I L$} \\
\hline São Paulo & Brasil & 5.965 .800 & 208.700 & 3,49 & 44 & 5.120 & 40,7 \\
\hline
\end{tabular}

* A fonte justifica o número elevado com a explicação de que se trata dos internatos oficiais, da Prefeitura (6.336), mais os de caráter privalo (4.261), perfazendo o total de 10.597 leitos.

Confirma-se aqui que, com todas as demais cidades, trata-se, do mesmo modo, com o total de internatos, oficiais e particulares.

extremo de pessoas por leito, ou seja, 109,2 pessoas. As demais cidades da Europa oferecem um leito para 19,8 a 20,6 pessoas; as dos Estados Unidos (excluindo México) um leito para 16,9 a 28,8 pessoas.

Tel-Aviv-Yafo está mais próxima dos Estados Unidos com o número de pessoas por leito, ou seja, 26,3, porém está mais perto da Europa quanto à proporção de pessoas de 65 anos e mais, 13,4\%.

Verificou-se que: nas cidades européias a proporção de pessoas de 65 anos e mais é maior do que nos Estados Unidos. Os recursos de leitos nos internatos, porém, 
BASTIAN, E. M. Internatos para a terceira idade - dados internacionais. Rev. Saude públ., S. Paulo, 13:60-2, 1979 .

aproximam-se bastante, com exceção de duas cidades com dados extremos. Há uma média de 25,2 pessoas por leito na Europa e 24,0 pessoas nos Estados Unidos; em São Paulo, mesmo tendo uma proporção baixa de pessoas na faixa etária de 65 anos e mais, $3,49 \%$, dispõe de um leito de internato para 40,7 pessoas, bem distante da escassez no México, D. C. e mais próximo de cidades como Viena, com 30,5, e New Orleans, com 28,8 pessoas por leito; os resultados conseguidos neste inquérito podem servir de ponto de partida para estudos interculturais sobre a problemática da assistência à população da terceira idade.

Bastian, E. M. [Nursing homes for the third age.] Rev. Saúde públ., S. Paulo, $13: 60-2,1979$.

ABSTRACT: The data on the total population and that of people 65 or older, the number of nursing homes for this latter group, and the number of beds in these homes in cities in Europe, the United States, and the Middle East is compared to equivalent data for the city of São Paulo, Brazil. The rate of the elderly population and number of persons per bed in nursing homes was of special interest to this inquiry.

UnITERMS: Aged. Homes for the aged. Nursing homes.

\section{REFERENCIAS BIBLIOGRAFICAS}

1. ANUARIO ESTATISTICO DO BRASIL. (Fundação IBGE) Rio de Janeiro, 1976 .

2. BASTIAN, E. M. Estudo dos aspectos da assistência a saúde da pessoa idosa em instituições não hospitalares do Município de São Paulo, Brasil. Rev. Saúde públ., S. Paulo, 11:444-54, 1977.

Recebido para publicacão em 05/09/1978 Aprovado para publicąão em 09/11/1978 